\title{
Capturing the Invisible: Heat, Steam and Gases in France and Great Britain, 1750-180o
}

\author{
Marie Thébaud-Sorger
}

Over the course of the eighteenth century the common perception of air, that invisible but omnipresent element of nature, experienced a profound change. This essay argues that a common field of knowledge emerged through the materialization of aerial fluids, including gases, steam and heat. This topic inspired the creativity of a hybrid milieu of practitioners, who extended the investigation of air while embedding it in public concerns. A growing culture of consumption, especially in urban contexts in France and Britain, helped nurture a number of new devices and apparatus aimed at mastering these fluids for various purposes and in everyday life. They offered the capacity to reshape the interplay between scientific results, social needs and political incentives, presenting new horizons for the public good and public health.

This essay reformulates assumptions (and raises questions) regarding the 'sites' where new approaches to air were forged. From the seventeenth century, air was closely linked to the rise of the experimental sciences. Calculating the weight and pressure of the air and understanding the vacuum, were crucial to a change of perception embodied in devices such as the air-pump. Imbuing immaterial air with a new kind of materiality fostered the emergence of "a set of practices which centered on the climate, meteorology, the atmosphere and electricity." According to Simon Schaffer, "aerial philosophy" played a major role in this change and "acted as a wider and grander theater of power and also as a space in which a new economy of understanding and control might operate." Discoveries in the 1770 of of various elastic fluids challenged and diffracted the category of "air" as a unified, natural body and, together with the identification of various gases, reframed the growing field of pneumatic chemistry. ${ }^{2}$ However, while the role of prominent European chemical practitioners in this story is familiar, this essay explores how investigations of air engaged the creativity of a less familiar and more heterogeneous set of practitioners,

1 Simon Schaffer, "Natural Philosophy and Public Spectacle in the Eighteenth Century," History of Science 21 (1983): 1-43, on 16.

2 Joseph Priestley, Experiments and Observations on Different Kinds of Air (London: W. Bowyer and J. Nichols, 1774).

(C) MARIE THÉBAUD-SORGER, 2018 | DOI 10.1163/9789004325562_005

This is an open access chapter distributed under the terms of the CC-BY-NC License. 
who engendered novel communities and new audiences around their inventions and devices.

To do this entails a methodological displacement through a focus on the sociomateriality of the devices through which this broad range of practitioners contained, investigated and manipulated aerial fluids, including small-scale inventions, machines and commodities such as lamps, ventilators, gas masks, firebombs, "œeconomic" stoves and furnaces. Discussion of specific cases draws on a body of printed ephemera - leaflets, advertisements, subscriptions, short essays, trade cards - and project descriptions sent to various societies, academies and societies of arts. The essay thus moves beyond tired distinctions between scientific and more commercial practices which were in fact closely interconnected. In this account the manufacture of certain technical inventions may be seen to have operated as both what Rheinburger has called an "experimental arrangement" and as a social and epistemological one. ${ }^{3}$ Considering "air" as a boundary object helps to formulate new assumptions about the epistemic nature of the devices that materialized invisible aerial fluids for a wide range of audiences. ${ }^{4}$ This enables a more general questioning of changes in perceptions of nature at the end of the eighteenth century, and the relationship between material and knowledge production, which entailed the co-construction of an investigative field. Mapping the intellectual and social milieux in which people engaged with materiality through the making, use and understanding of small-scale devices and the substances they contained reveals how changes occurred at the level of daily practices.

This essay centers on an understanding of aerial fluids through technical work that practically interacted with air qua matter. André Leroi-Gourhan's anthropology of techniques is an inspirational source for the essay's approach. ${ }^{5}$ The specificity of aerial fluids (such as rarefied air, noxious air, expanded air, inflammable air) inspired specific operative work on the shape and composition of devices (such as containers and vessels) designed to capture, investigate and make use of the fluids. Reinterpretating chemistry from the angle of technology recalls the pattern of Catherine Jackson's 'glass revolution' - the way in

3 Hans-Jörgen Rheinberger, "Experiment, Différence and Writing I," Studies in History and Philosophy of Science 23 (1992): 305-331, on 309.

4 Susan Star, James Grisemer, "Institutional Ecology, 'Translations' and Boundary Objects: Amateurs and professionals in Berkeley's Museum of Vertebrate Zoology, 1907-39," Social Studies of Science 19 (1998): 387-420.

5 André Leroi-Gourhan, L'homme et la matière (Paris: Albin Michel, 1943). 
which materially embodied processes eventually transformed the whole understanding of 'air'. 6

The essay begins by examining how, on both sides of the English Channel, practitioners proposed a diverse array of commodities and objects that emerged from their investigations into air. These offered practical improvements in public and private everyday life through different means of mastering aerial fluids. Subsequent sections consider how the effects of these objects on air reshaped the social and material arrangements in which they were developed. Focusing on inventive practices makes clearer transfers of skills and hybridizations that occurred between entrepreneurs, amateurs and craftsmen. The careers of Ami Argand and Flavien Marie Scanegatti demonstrate this with particular clarity. While material devices provided the means to do experiments and create narratives about air, they also raised questions regarding both the social and intellectual boundaries of chemistry along with the knowledge they helped to forge.

\section{Sites of Air's Commodification}

Historians have recently attended to an "aerial sensibility" that emerged over the course of the eighteenth century, focused particularly on environmental medicine - a field that connected issues of health, a global understanding of weather and an emergent pneumatic chemistry. ${ }^{7}$ The changing understanding of 'airs' in this period has been extensively studied from the point of view of the prominent European chemists of the period. ${ }^{8}$ Studies of the intersection

6 Catherine M. Jackson, “The 'Wonderful Properties of Glass,", Isis 106 (2015): 43-68. Technology will be used here with its original meaning of techno-logos, "science of operations" or "science of the arts", rather than "applied science". See Eric Schatzberg, "From Art to Applied Science," Isis 103 (2012): 555-563.

7 Simon Schaffer, "Measuring Virtue: Eudiometry, enlightenment and pneumatic medicine," Andrew Cunningham and Roger French, eds., The Medical Enlightenment of the Eighteenth Century (Cambridge: Cambridge University Press, 1990), 281-318; Marco Beretta, "Pneumatic vs. 'aerial Medicine': Salubrity and respirability of air at the end of the eighteenth century," Nuova Voltiana: Studies on Volta and his time, Pavia, 2 (2000): 49-71; Vladimir Jankovic, Confronting the Climate. British air and the making of environmental medicine (New York: Palgrave Macmillan, 2010); Jan Golinski, British Weather and the Climate of Enlightenment (Chicago: University of Chicago Press, 2011).

8 Bernadette Bensaude-Vincent, Isabelle Stengers, Histoire de la chimie (Paris: La Découverte, 1993); Marco Beretta, The Definition of Chemistry from Agricola to Lavoisier (Canton, MA: Science History Publications, 1993). 
of their practices with the social milieux of instrument-makers and artisans have shed light on dynamic collaborations but also revealed tensions and ways in which knowledge was challenged by new measurement practices. ${ }^{9}$ However, little attention has been paid to the role of inventive practices that were supported by a growing market for new consumer commodities. Entrepreneurs, amateurs, architects, physicians and a large community of skilled artisans including instrument-makers, stove and pump manufacturers, distillers, coppersmiths and tinsmiths all engaged with aerial substances. They designed objects dedicated to mastering the elements, including a wide range of devices for cooking, heating rooms, preventing and extinguishing fires, fumes and every type of suffocation. They used steam and included small appliances dedicated to hygiene and comfort (steam baths, ventilators, lamps, portable stoves, and so on). This "commodification of air", recently noted by Vladimir Jankovic, spread in the second half of the eighteenth century..$^{10}$ It fostered public interactions in various sites: public lectures, workshop displays, repositories of the new sociabilities of improvement, demonstrations and trials occurring in situ - on river banks, in gardens, parks, at a cesspool. Audiences interacted at these sites with devices that have not usually been considered as tools of pneumatic chemistry investigation; nor have these audiences been recognized as participants in a new ontology of air, which emerged at this time.

Recognizing changes in the culture of consumption permits a different approach to these sites so that, rather than exploring separate spaces, it is possible to ask how evolving practices forged links between various spaces such as laboratories, workshops, factories and public squares. Diverse fields of action, such as medicine, architecture, urban safety and industry, which have until now been studied separately, are thereby seen as connected. Indeed, from this perspective, aerial fluids can be seen to have entailed a common approach. Writing in the 1940s, the anthropologist André Leroi-Gourhan proposed that fluids ought to be considered as matter if they could be decanted and poured. This entails expanding the category 'fluids' beyond liquids to include all kinds of containable materials. Leroi-Gourhan's interest in prehistoric tools in the

Larry Stewart, "Ordinary' People and Philosophers in the Laboratories and Workshops of the Early Industrial Revolution," Margaret C. Jacob and Catherine Secretan, eds., In Praise of Ordinary People: Early Modern Britain and the Dutch Republic (New York: Palgrave Macmillan, 2013), 95-122; Lissa L. Roberts, "The Death of the Sensous Chemist: The 'new' chemistry and the transformation of sensuous technology," Studies in History and Philosophy of Science Part 4 (1995): 503-529; H. Otto Sibum, "Les gestes de la mesure. Joule, les pratiques de la brasserie et la science," Annales Annales. Histoire, Sciences Sociales 4-5 (1998): 745-774.

10 Jankovic, Confronting the Climate, p. 70 (see note 7 ). 


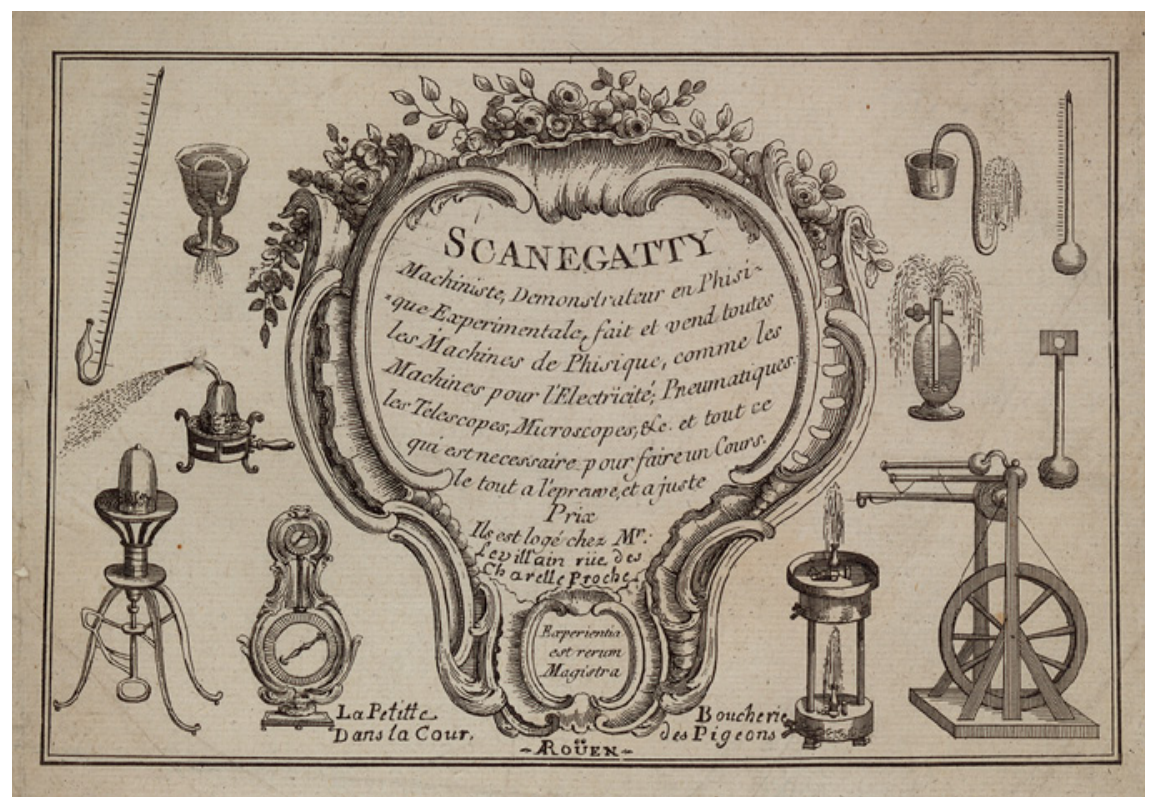

FIG URE 3.1 Anon., Trade Card of Scanegatty, Machine Inventor and Demonstrator of Physics Apparatus, c. 1775; etching and engraving on paper; $160 \times 202 \mathrm{~mm}$; Waddesdon, The Rothschild Collection (The National Trust) Bequest of James de Rothschild, 1957; acc. no. 3686.1.65.123. Photo: University of Central England Digital Services (C) THE NATIONAL TRUST, WADDESDON MANOR.

1940s led him to single out a pattern of technological action, distinguishing social-technical human activities according to their relation to different types of matter. This approach proposed a classification of various "gestures" and "operations" that are done to matter. Consequently, Leroi-Gourhan defined fluids by the processes developed to enable their containment and circulation, that is, through the vessels in which they were contained. For certain eighteenth-century practices, diverse forms of aerial fluids, vapors and emanations might be understood in this way, through the objects and techniques used to capture, investigate and manipulate them.

The trade card of Flavien Marie Scanegatti, an Italian-born instrumentmaker who settled in the French city of Rouen in the early 1760 s, perfectly illustrates this perspective (Fig. 3.1). ${ }^{11}$ It depicts the instruments that could be found in his shop, described two decades later by Arthur Young as a "consider. able room furnished with mathematical and philosophical instruments and gatty, Machine Inventor and Demonstrator of Physics Apparatus," n.d., c. 1775 . 
models."12 Scanegatti used these in the public physics lectures he advertised regularly in gazettes, where he performed curious experiments for local audiences with electricity, hot air and inflammable air. His trade card presented various instruments including a barometer and thermometer, and demonstration apparatus such as an air pump, an æoliopyle on a stand, an electrical machine with a wheel, a glass tube with measurements and a pot of water with a siphon. The Journal de l'abbé Rozier reported on other Scanegatti inventions such as an aéromètre or pèse-liqueur (scales designed to precisely measure the weight of several liquid substances), and, in 1774, new medical tools such as an improved "fumigatory apparatus" to save people from drowning. Scanegatti's activities extended beyond his shop door, taking in industrial sites for the needs of local production (textiles machines, enamel at Saint Sever); industrial chemistry, with the development of a lead chamber for sulfuric acid production; and a plaster kiln fueled by coal - an invention for which he performed experiments in front of local elites and in academic accreditation exams for the Bureau du commerce and the Académie royal des sciences..$^{13}$ He also undertook the scientific supervision of balloon experiments in 1784 on behalf of the Avignon city council, where he had been called to work on hydraulic projects. ${ }^{14}$ There were continuities across this diverse and impressively creative activity, which has normally led to him being described as eclectic. ${ }^{15}$ Motivated by utility and industry, a good part of the inventions he designed, despite their heterogeneous appearance, were connected by a common desire to capture fluids and enable their transformation.

Situated between what is retrospectively identifiable as philosophical curiosity and craft-based practicality, the creative activities of Scanegatti appear exemplary of an intermediary world, of interactions between local academies, artisanal elites and industrial networks. The career of the entrepreneur Ami Argand followed a similar trajectory, although Argand's reputation was not

Arthur Young, Travels in France, During the Years, 1787, 1788, 1789 (London: George Bell and Son, 1909), 142 (5th October 1788). Thanks to John Perkins for his help on Scanegatti.

Archives Nationales de France, Paris (subsequently A.N.F), series F12-238o, Scanegatti, "Application du charbon de terre à la cuisson du plâtre," 1786 à 1788; Archives of Cnam, T.666, 24, p. 2 engravings.; Academie des sciences archives, Paris, "Pochette de séance, 31st January 1787: Fourneau pour cuire le plâtre de Scanegati," (Report from Vandermonde, Sage et Monge, 3rd February 1787).

14 Courrier d'Avignon 26 (Tuesday 3oth March 1784): 108; Air and Space Museum Archives, Le Bourget, Montgolfier folders, XV-33, "Letter of the marquis de Brantes to Joseph de Montgolfier, Avignon, 7th April 1784."

15 Frédéric Morvan-Becker, "L'École gratuite de Dessin de Rouen, ou la formation des techniciens au XVIIIe siècle" (PhD Thesis, Université Paris VIII-Saint Denis, 2010), 779-79o. 
built up in one place, but through traveling across Europe to develop his invention of a lamp using double air currents. ${ }^{16}$ The son of a Geneva watchmaker who was educated by Horace-Bénédict de Saussure, Argand's interests covered a wide range of connected chemical and mechanical processes, such as distillation, combustion and evaporation. He made the acquaintance of the Montgolfier brothers, and Etienne Montgolfier engaged his help with hot-air balloon experiments in Paris in autumn $1783 .{ }^{17}$ Louis-Paul Abeille, a former factory inspector and at that time the French royal government's Secretary of Commerce, recorded his visit to their open-air workshop situated in the garden next to Jean-Baptiste Reveillon's famous wallpaper factory in the Faubourg Saint Antoine. Abeille described a diverse community of actors surrounding the balloon prototype, including state and city administrators, entrepreneurs such as Argand and Reveillon, a foreman of the factory Giroud de Villette, apothecaries such as Quinquet and Lange, and Meusnier de la Place, a mathematician and correspondent of the Académie Royale des sciences, not to mention neighbours and curious onlookers. ${ }^{18}$ Leaving Paris for England, Argand sought the support of Boulton and Watt, who helped him take out a patent for his lamp that he later lost in a trial. Returning to France he obtained a privilège to set up a lamp manufactory in Versoix in $1787 \cdot{ }^{19}$ Projecting for the lamp in Birmingham and London was punctuated by other experiments - first with air-pumps and gas balloons, which were shown to George III at Windsor in November 1783 , and then with the large-scale production of inflammable air for Lunardi and Blanchard's public balloon ascents made in London in $1784 .{ }^{20}$ Argand moved through a variety of different contexts in which aerial fluids

16 Michael Schrøder, The Argand Burner: Its origin and development in France and England, 1780-1800: an epoch in the history of science illustrated by the life and work of the physicist Ami Argand, 1750-1803 (Odense: Odense University Press, 1969).

Charles Coulston Gillispie, The Montgolfier Brothers and the Invention of Aviation, 17831784 (Princeton, NJ: Princeton University Press, 1983); Marie Thébaud-Sorger, "Amitiés, entraides et circulations techniques: les affinités électives de l'entrepreneur Argand," Michel Cotte, ed., Circulations techniques, en amont de l'innovation: Hommes, objets et idées en mouvement (Montbeliard: Presses Universitaires de Franche-Comté - ut BelfortMontbéliard, 2004), 111-128.

Louis-Paul Abeille, Découverte des lampes à courant d'air et à cylindre par M. Argand (Geneva: 1785), 13 .

19 John Wolfe, Brandy, Balloons, and Lamps: Amy Argand, 1750-1803 (Carbondale: Southern Illinois University Press, 1999).

20 Air and Space Museum Archives, Le Bourget, Montgolfier folders, XIII-39-45: letters from Argand to Etienne de Montgolfier, 1783-1785. 


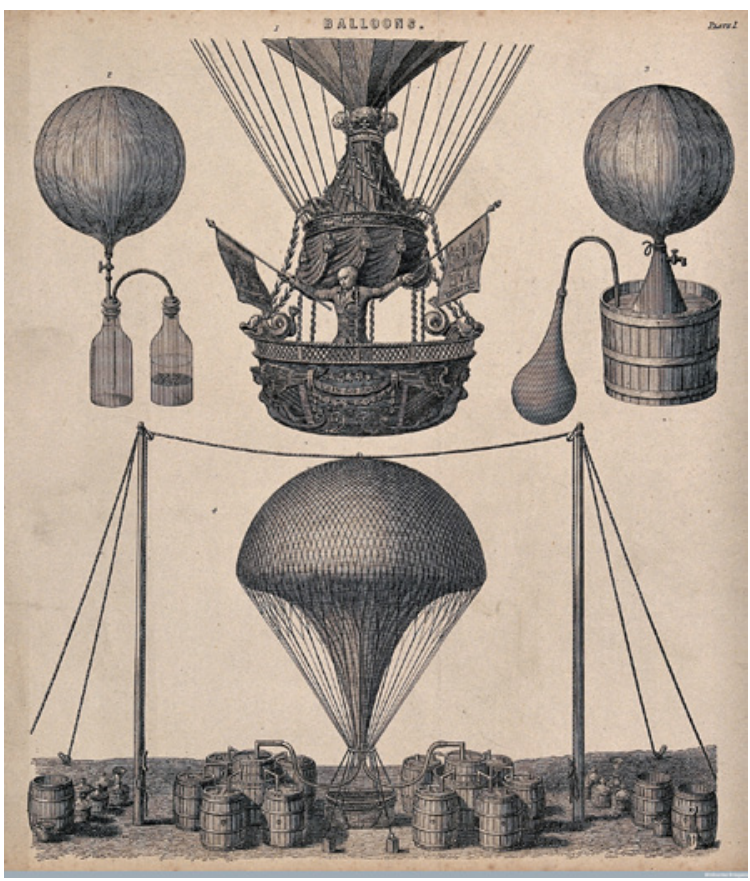

FIGURE 3.2

Balloons. Engraving. [s.n.] [S.l.]. Wellcome Library, London, Iconographic Collections, ref. ICV No 41432.

were worked on and exhibited, including factories, gardens, public squares, shops and workshops.

What was original in this period was the way a dynamic set of actors from various backgrounds, including entrepreneurs, instrument-makers, craftsmen, merchants, servants, noble amateurs and apothecaries, moved from one field of practice to another, transferring skills and knowledge as they did so. They thereby helped to establish common interests among large audiences, which fostered intersections between the pleasure of curiosity and industrial achievements, private comfort and public concerns. These intersections created a constellation of "sites" around their objects where the same processes could be staged and reinterpreted in a variety of ways. Many practitioners, such as Argand and Scanegatti, maintained complex relationships with academics, seeking out support, recognition, institutional and social credit and their further involvement in projects. Their practices were shaped by porous institutional, political and territorial boundaries and by intellectual tensions, which differed between Britain and France. In France, for instance, the Academy's pre-eminence in the evaluation of inventions was on the increase ${ }^{21}$ But

$21 \quad$ Liliane Hilaire-Pérez, "Technical Invention and Institutional Credit in France and Britain in the Eighteenth Century," History and Technology 16 (2000): 295-306. 
while local configurations diverged in many respects between Britain and France, they were nevertheless forged by symmetrical dynamics.

In the 176 os fire hazards, noxious air, hygiene and health became prominent topics in society. Individuals engaged with these issues prompted a wide circulation of processes and forged new audiences, encountering in particular the interest of "alternative" new sites of sociability, such as the prosperous London Society of Arts, founded in 1757, and many similar societies across Europe. Scanegatti promoted a scheme to open a Société des arts in Rouen affiliated with the Parisian Société d'émulation pour l'encouragement des arts (1777-1782), an ephemeral society founded by a physiocrat, the Abbé Baudeau. ${ }^{22}$ Embodying a public consisting of mixed audiences of aristocrats, savants, elite artisans and men who exercized the machinery of power, these societies were particularly concerned with issues related to the public good, while at the same time increasing support for patriotic and capitalist businesses. ${ }^{23}$ Offering new spaces of legitimation, they launched contests, offered rewards and issued medals. They were sensitive to supporting all kinds of artifacts in which technological improvement and the management of global reform were at stake, such as ventilation and rescue apparatus, extinguishers and fire engines, stoves and furnaces. For instance, William White Esquire approached the special committee established by the London Society of Arts on "hand ventilators" with an "air machine" of his invention. (The committee ran for several years, organizing a prize for this category in 1791-1792.) Besides being exhibited in his workshop, White's machine was on display in the society's repository, alongside similar devices for comparison. ${ }^{24}$ White also approached the Humane Society, which gave him several accreditations in support of the development of a patent. ${ }^{25}$ These efforts coincided with the growth of philanthropic societies dedicated to resuscitating drowned people in Amsterdam, Hamburg,

22 A.N.F., T*160.5, Grand registre du secrétariat de la société d'émulation de l'abbé Beaudeau depuis 1778 à 1782, "Mémoire de Mr Raymond de St Sauveur sur une proposition de Mr Scanégatti de Rouen sur un comité provincial a établir en cette ville, Retenu au comité d'inspection, 10 fev. 1778."

Liliane Hilaire-Pérez, L'Invention technique au siècle des Lumières (Paris: Albin Michel, 2004).

24 Diary or Woodfall Register (1792) Tuesday 5 th June.

25 London Metropolitan Archives, 4517/A/01/01/oo1, Minutes of the Humane society, meetings of the 3oth January 1776 and 7th May 1783; Royal Society of Arts, Society of arts archives, Loose letters, PR.MC/101/10/512, "Letter from William White about his air machine," 3oth January 1792; Extracts from the reports of the Royal Humane Society, with certificates, letters, \& $c$. which fully evince the utility of an air machine, or patent ventilator; invented and sold by William White (1794). 
London, Paris and Geneva. ${ }^{26}$ Founded mostly by physicians, they dealt with issues of asphyxia and reanimation and scrutinized various inventions including gas masks, fumigation boxes and fumigation apparatus, such as that improved by Scanegatti, or conceived by the physician and alderman PhilippeNicolas Piat in Paris in the $1770 .^{27}$

In England and France, a similar concern emerged regarding risk and safety, the mastering of new energies and a shared desire to discipline urban areas. ${ }^{28}$ Identifying technical devices with the capacity for improvement enabled a new marketing dynamic based on claims to be able to transform the immediate environment. Through the commercialization of various commodities, apparatus and objects, a new material culture took root in the social and urban landscape of the eighteenth century that gradually changed people's relationship to the elements of nature. Infused with this aerial knowledge for large audiences, for whom the natural world was submitted to intensive changes, each invention intersected with these different spheres. Producing an apparatus or new commodity using 'airs' was the result of a complex reception and production process that made their achievement possible and, in return, shaped communities around their materiality.

\section{Devices Shaping Communities}

Through the design of devices an evolving sociomateriality situated the "air" in a densely populated field that highlighted the possibilities offered by aerial

26 Luke Antony Francis Davison, "Raising up Humanity: A cultural history of resuscitation and the Royal Humane Society of London, 1774-1808" (PhD Thesis, University of York, 2001).

27 Philippe-Nicolas Pia, Détails des succès de l'Établissement que la ville de Paris a fait en faveur des personnes noyées (Paris: S. Yves, 1773) with an engraving of his "Boîte-entrepôt"; "Boite fumigatoire de Gardanne," Gazette du commerce, de l'agriculture et des finances 84 (1778): 668-669 (2oth October); On the disinfecting devices of Guyton de Morveau and Dumotiez, see the essay by Elena Serrano in this volume.

28 Sabine Barles, La ville délétère. Médecins et ingénieurs dans l'espace urbain, XVIIIe-XIXe siècles (Seyssel: Champvallon, 1999); Catherine Denys, Police et sécurité au XVIIIe siècle dans les villes de la frontière franco-belge (Paris: L'Harmattan, 2002); Marie ThébaudSorger, "Innovation and Risk Management in Late Eighteenth-Century France: The administration of inventions in French cities at the end of the ancien régime," Christelle Rabier, ed., Fields of Expertise. A comparative history of expert procedures in Paris and London. 1600 to present (Cambridge: Cambridge Scholar Press, 2007), 261-189; Thomas Le Roux, Le laboratoire des pollutions industrielles. Paris, 1770-1830 (Paris: Albin Michel, 2011). 
substances. A flourishing consumption culture encouraged many multi-functional inventions in which aerial fluids were used, fitting within a general agenda of improvement. These new apparatus appeared not only as goods ready for sale on the market but also as unfinished objects whose completion would require wider participation. Consumers, experts and administrators would be involved in such practices, which would also generate communities of hybrid actors and allow different manufacturing techniques to converge into collaborative enterprises that might lead to pioneering work on various materials.

A perspective that includes technology, rather than just thinking about gases themselves, makes it possible to reveal the inventions and materials used to capture and thereby frame them. Adapting materials articulates a way of acting upon aerial matter which must be understood in terms of operations such as wood turning, glass blowing and polishing, tinning, welding and varnishing, which required expert knowledge and much skill in order to adapt the reaction between the air enclosed and the material used. These operations, according to Leroi-Gourhan, are embodied in concrete local and historical configurations. The effectiveness of devised craft methods depended precisely on the physical specificities of each kind of fluid, which entailed appropriate constructive "processes", aimed at the performance of sealing, resistance, capture and circulation. They inspired pioneering work with various shapes and materials (valves, sheet metal, glass and metal tubes, various chimneys, varnishes, soft fabrics, leather bellows, burners) that created an "operational chain": a set of sequences that performed an effective action upon matter. ${ }^{29}$

Balloon workshops embodied these processes perfectly and, since the invention of hot-air balloons in 1783, opened up a new and stimulating field of research. These balloons involved complex technology - though it must be added that components thereof might be objects that were traditionally available and quite mundane. ${ }^{30}$ This included wooden barrels in which sulfuric acid was diluted with water, and then poured onto iron filings to produce inflammable air; pipes intended to capture gases and conduct them into a soft fabric balloon, covered with a varnish that had to be elastic enough to allow a variation in pressure and prevent the escape of the volatile air inside and any risk of explosion; and tin-plate cooling systems designed to avoid the danger-

29 This concept was also part of André-George Haudricourt's approach, La technologie, science humaine. Recherche d'histoire et d'ethnologie des techniques (Paris: Maison des sciences de l'homme, 1987), and was related initially to French sociologist Marcel Mauss and the techniques of the body.

30 See Simon Werrett's essay in this volume. 
ous heat that occurred during chemical reactions, and which also purified the carbonic gas. The processes at stake in these machines were part of a research trend associated with the industrial development of new substances, which included not only the chemistry of gases, but also sulfuric acid and waterproof varnish made from rubber: in short, chemical practices that were deployed at several levels of collaboration ${ }^{31}$. Every experiment with a balloon required the production of a prototype, the making of which involved a mixture of entrepreneurs, provincial amateurs, semi-learned people and manufacturers, chemists and craftsmen, often financed by public subscription. ${ }^{32}$ Much more than a commercial practice, this procedure enabled people to engage with the processes being developed. Prototypes enhanced their inventor's credit, and were used for many other inventions, such as the air pump, ventilator and steam engine. ${ }^{33}$

Abeille's account of the Reveillon factory describes the energy that Argand had put into his supervision of Montgolfier's construction of the hot air balloon, which involved many impassioned exchanges with the people gathered around the machine. To all those present, the analogy between the hot air balloon and the process involved in Argand's lamp seemed obvious. The flame was stimulated by vital air (oxygen), and issued by way of the resistance of the walls of the machine. The way in which, in general, containers behaved through a transformation of temperature and composition of the air enclosed was also crucial for the lamp. Argand's lamp was also a composite object, made of glass, sheet metal, welding, varnish, wheels, wick, and oil. The tube was a crucial issue. Argand wished to replace the metal chimney located above the flame with a glass one, which might help to increase the effectiveness of the light. In order to develop a suitable material, he needed to find glass able to resist alternate heating and cooling. British knowledge of flint glass might reveal the solution, so Argand moved to England to overcome this obstacle and to find

31 Leslie Tomory, Progressive Enlightenment. The origins of the gaslight industry, 1780-1820 (Cambridge, MA: MIT Press, 2012).

Marie Thébaud-Sorger, L'aérostation au temps des Lumières (Rennes: Presses Universitaires de Rennes, 2009).

33 See, among many examples, Thomas Tidd, Considerations on the Use and Properties of the Eolus a New Invented Portable Machine for Exchanging and Refresching the Air of Rooms, \&c. (London: J. Reeves, 1755); Anon., "Pompe nouvelle et portative pour les incendies et arrosements," Journal de littérature, des sciences et des arts par Mr. l'abbé Grosier (1780): 358-359, referring to a subscription opened in Paris by a mechanic, Charpentier. Lissa Roberts also discusses this entrepreneurial process in "Geographies of Steam: Mapping the entrepreneurial activities of steam engineers in France during the second half of the eighteenth century," History and Technology 27 (2011): 417-439. 
adequate support to develop his invention. Similar issues were raised and discussed widely among various audiences and through transnational networks of expertise. Argand's connections extended into French-English capitalism, networks of administrators, savants and investors who were all crucial in chemistry's evolution in the last decades of the century.

Synergies, analogies and systematization emerged in the development of aerial contraptions. These objects constituted a common taxonomy of different shapes (vessels, tubes, connecting pipes, spring, bellows, blades and so on) and a repertory of know-how that could be put to diverse uses. Coating and varnishing, critical techniques for the containment of air, emerged as prominent fields of investigation relating to fireproofing and the production of airtight seals. Every element in one invention could potentially be transferred to another. Inventions were composite artifacts, and adaptable to a wide range of applications at different scales (not to mention prices). Inventors then shaped communities around their objects employing many common forms of action such as display, advertising, seeking the approval of various societies, or engaging in other spheres of accreditation. Commercial literature played a crucial role in the dissemination of these processes: through advertisements, leaflets and calls for subscription, entrepreneurs required consumers to cultivate the ability to understand, compare and judge the relevance of a device. ${ }^{34}$ Objects were bonded together. While drawing attention to Argand's great assistance in gas-making for Blanchard's balloon in London, an article published in the Courier de l'Europe advertised his new lamp in an enthusiastic way. ${ }^{35}$ Artifacts such as lamps, stoves and ventilators were designed on the border between private and public concerns. The announcement of Whites' "air machine" claimed that it was conceived to serve in various contexts where air was confined in public buildings, ships, hospitals and mines, and also in private rooms. He targeted not only London markets, but also the colonies. This kind of device thus existed at the intersection of health and private comfort, in addition to being intended as an improvement for people at work. Yet this polysemy was based on one coherent principle: that invisible air became palpable through devices and their components (here the fan blades stirring the air) producing an obvious effect that everyone could grasp and comprehend. Many kinds of devices were designed to fight asphyxia. Inventors acted either

34 Liliane Hilaire-Pérez, Marie Thébaud-Sorger, "Les techniques dans l'espace public. Publicité des inventions et littérature d'usage au xvinte siècle (France, Angleterre)," Revue de Synthèse 127 (2006/2): 393-428; Jeffrey R. Wigelsworth, Selling Science in the Age of Newton: Advertising and the commoditization of knowledge (Farnham: Ashgate, 2010), 7. 
on the surrounding "air" or they invented equipment for the exposed body, such as the fumigator apparatus. The description of Scanegatti's apparatus involved "flexible tubes", "cannula" and a "bellows" designed to inject tobacco smoke into the bodies of drowned people to help recover respiration after drowning. ${ }^{36}$ The opening up of a new understanding of 'airs' addressed the issue of being able to breathe, in both a literal and a metaphorical sense, in the human and the social body.

Capturing, changing and making air drew on a wide range of actions and a new comprehension of the nature of aerial substances, which occurred in various social spaces on various scales. Bringing these together reveals a continuity, where linking one object to another in a whole system made sense. Emerging through decomposition and re-composition, the staging of inventions presented relationships between simple natural bodies in a new light, initiating a shift in sensitive and conceptual frameworks of material life. Scanegatti offered lessons in which he presented this kind of interconnection by exploiting the intrigue of striking experiments.

Among the many items to be exhibited before the eyes of the public will be a hydraulic pendulum of very regular movement that will act as an alarm in the morning, via two small canon blasts, which light a vessel or lamp filled with spirits, which heats a small pot of broth during the time it takes to get dressed, which will be ready to drink at the end of one's toilette. ${ }^{37}$

Mastering this operative sequence on a small scale set up the wonderful power of working with fluids, by means of a curious mechanical arrangement, using "explosions", "liquor", "heating" and "evaporation" to achieve individual accomplishments like waking up and making a pot of broth. By using the possibilities offered by "aerial fluids", a new kind of relationship with materials emerged for large audiences, changing the way in which they could be understood, mastered and turned into an effective action.

Small-scale inventions, even those that were amusing and curious, encouraged a common way to explore the new materiality of air and its effect upon daily improvements, where mastering these substances played a major role "in

36 "Noy," Félix Vic d'Azyr, Encyclopédie méthodique, 8 vols. (Paris, 1783), vol. 5, 366; JosephJacques Gardane, Gazette de santé, contenant les nouvelles découvertes sur les moyens de se bien porter \& de guérir quand on est malade (Paris, 1774), 298.

37 Notice of Scanegatti's course of experimental physics beginning 1st July 1764. Annnonces, affiches et avis divers de Normandie(1764), 20. 
the providential economy of nature." 38 Scanegatti later explored this creativity by tackling objects for urban management through his fumigation apparatus and his furnace, which dealt with the crucial oeconomic issue of the shortage of wood for production. As part of the promotion of his plaster kiln in 1786, he organized extensive trials in front of the king's representative in Rouen, several manufacturers, town aldermen and local men of science. This demonstrated further what kind of achievement the mastering of combustion could provide when embedded in a political œconomy that dealt with the management of energy and the search for fuel substitutes. ${ }^{39}$ Seemingly technical practices would actually change the sociomaterial process of knowledge production and contribute to a transformation in the perception of these invisible substances.

\section{'Airs' as Boundary Objects}

The materiality of 'airs' could only be revealed when they interacted with other materials. As Lavoisier wrote in his first essay on elastic fluids in 1777, "They escape the sense of touch, except where their resistance to bodily movement renders them discernible and to a certain extent palpable." ${ }^{40}$ By working with 'airs' (vaporized substances, noxious air, hot air) via their devices, practitioners tried to track this 'materiality', simultaneously producing experimental systems in which the identification of these airs' properties was put to the test. Partly because they presented prototypes, projects and inventions under development, each artifact could act as an experimental tool, similar in some ways to the "generator of surprise", to recall Rheinberger's category. ${ }^{41}$ The degree of uncertainty inherent in the success of these apparatus and devices made their performance in various sites a source of permanent wonder. Their effectiveness depended on many material arrangements that constantly needed to be re-adjusted.

Inventors scrutinized the interaction between 'airs' and the materials of the containers they adapted. Aerial fluids, unlike a liquid with an identical density throughout, diverged because they might be made of several fluids with

\footnotetext{
38 Golinski, British Weather, p. 161 (see note 7).

39 See the essay by Roberts and Van Driel in this volume.

40 Antoine-Laurent de Lavoisier, "Expériences et observations sur les fluides élastiques en général et sur l'air de l'atmosphère en particulier," (1777), Jean-Baptiste Dumas and Edouard Grimaux, eds., CEuvres de Lavoisier (Paris: Imprimerie nationale, 1862-93), vol. 5, 271.

Rheinberger, “Experiment, Différence and Writing I.," p. 307 (see note 3).
} 
different properties and densities. Therefore practical observations and work on various technical arrangements led practitioners to formulate observations according to these distinctions. Air being perceived as a single entity seems to have been diffracted by various components resulting from the heating process, such as the vaporization of various liquid substances, which created invisible fluids, and combustion, which liberated several substances including fumes and invisible components such as the hypothetical air du feu, equated by some with phlogiston. The relationship between aerial gases and atmospheric air was not resolved by the discovery of new gases such as vital air (oxygen), noxious air (carbonic gas), and various inflammable 'airs' (such as hydrogen and methane). ${ }^{42}$ The idea that air was composed of several chemical elements only emerged gradually and in the meantime, ideas about air interacted with inventive practices. Observers were able to record accurately how 'airs' changed the vessels in which they were contained, through corrosion, condensation, fermentation and inflammation. In response, they sought out materials that could maintain a flame, avoid toxic emanations, reduce fumes or exploit possible motions.

These dynamic processes engendered a wide range of experiments, in surface treatments or ingenious connecting mechanisms such as flexible strips and elastic springs. However, the behavior of invisible aerial fluids in their devices raised many assumptions due in part to this feature of invisibility. Pneumatic chemists undertook a tests to define the different properties of elastic fluids, through reactions with combustion (explosion, extinction) made thanks to the possibility of isolating them in glass vessels to carry out analysis. Other practitioners used their technical devices to explore the same properties, with opposite expectations: for instance, to avoid explosions or to restore the vivacity of a living organism. They scrutinized the effects that capturing air made possible, such as the elasticity that provided motion when air was compressed. They sought to master 'aerial matter' while experimenting concretely with the behavior of invisible aerial fluids that revealed their different natures and compositions.

Rather than considering inventions as applications of scientific knowledge, we need to consider how seemingly technical practices changed the sociomaterial process of knowledge production and contributed to the understanding of these substances. Such practices - and the objects they engaged - often

42 Maurice Crosland, "Slippery Substances.' Some practical and conceptual problems in the understanding of gases in the pre-Lavoisian era," Frederic Lawrence Holmes and Trevor Harvey Levere, eds., Instruments and Experimentation in the History of Chemistry (Cambridge, MA: MIT Press, 2000), 79-89. 
pre-empted theory, as was the case for the understanding of heat and steam, or the nature of noxious air. Long before any chemical identification of carbonic gas, for example, the link between an understanding of 'atmospheric air' and 'health' was made through practical research into ventilators such as those proposed by Stephen Hales. ${ }^{43}$

Combustion processes were at the heart of chemical practices. The reaction of "air", fire and various materials and substances remained a central issue. Understanding the role of air in combustion was crucial for the design of many devices, which dealt with producing heat and fire, whether they were intended to extinguish a flame, or conversely to maintain it while circulating the heat produced. Far from being restricted to an empirical level of practice, practitioners engaged with newly generated knowledge of pneumatic chemistry. Activating fire with air was at the core of many apparatus, especially lamps, as highlighted by Argand's lamp. Argand was engaged in enthusiastic discussions with Meusnier de la Place during Montgolfier's experiments in Paris in 1783 , especially concerning the "action on dilated air by fire", the vaporization of substances, and the formation of droplets condensing on the sides of the fabric envelope that particularly caught their attention. For Argand, as for Meusnier, who was working at that time with Lavoisier on the experiment of the decomposition and recomposition of water, vapor was related to water, understood as being composed of vital air and inflammable air. ${ }^{44}$

Elasticity was particularly complicated to comprehend because it could be and was approached from both a physical and chemical standpoint. Lavoisier, among others, moved between these approaches in the pattern he proposed regarding aerial elastic fluids and, in particular, the property of many acids vaporized under the effect of a change of temperature. ${ }^{45}$ By the end of the century, a permanent porosity between physical and chemical ideas concerning the states and composition of matter existed in the category of fluids. As Robert Fox demonstrated in his book on the caloric theory, a chemical approach was maintained for a long time in the understanding of heat. ${ }^{46}$ Thus while many practitioners did not identify themselves as chemists, a large community worked with the materiality of invisible aerial substances, exploring

43 Stephen Hales, A Description of Ventilators: Whereby great quantities of fresh air may with ease be conveyed into mines, goals [sic] hospitals, work-houses and ships, in exchange for their noxious air, which was read before the Royal Society in May, 1741 (London: W. Innys, 1743).

44 Abeille, Découverte des lampes à courant d'air (see note 18).

45 Lavoisier, "Expériences et observations sur les fluides élastiques" (see note 40).

46 Robert Fox, The Caloric Theory of Gases from Lavoisier to Regnault (Oxford: Oxford University Press, 1971). 
not just their behavior but also their nature. The chemical knowledge of an "engineer" such as James Watt, for instance, was relatively great, exemplifying the fact that we need to overcome the anachronistic separation between physics and chemistry. ${ }^{47}$ 'Airs' were boundary objects that shaped the field of knowledge in addition to distinctions between practitioners.

Argand brought the evidence of his ability to transgress apparent boundaries between an empirical approach and chemical knowledge while performing practical work. Understanding perfectly the role of oxygen in combustion as he did, he qualified as the most appropriate person to supervise the chemistry required by ballooning projects, helping to manage balloon ascents in London by mixing the diluted sulfuric acid in each barrel with an iron stick in order to accelerate the hydrogen production process. ${ }^{48}$ Argand's activities illustrate that the processes involved in mastering heat and the production, evaporation and manufacture of gases were linked by an exploration of the risks they entailed, such as explosion and flammability. They simultaneously point to the social dimensions of such work. While Argand took part in the Coffee House Philosophical Society in London and befriended the Lunar Society group in Birmingham, especially Priestley, his integration may have been easier in England than in the intellectual surroundings of the French Académie des sciences where the reform of empirical practices of chemistry was at stake. ${ }^{49}$ However the majority of relations between established men of science and various practitioners involved close interactions, especially in provincial cities, in France and Britain alike. Provincial French academies such as those in Nancy or Rouen, which admitted Scanegatti as a fellow in 1775, offered a favorable framework of convergence for scientific and practical arts, fortunes and talents. ${ }^{50}$ Recognized as "a fine glass blower," a skill necessary for the success of meteorological experiments that he helped to perform, Scanegatti also earned recognition among the elite of Rouen for his lectures in physics, and demonstrations of his "fumigatory apparatus", which focused particularly on the

47 David Philip Miller,James Watt, Chemist: Understanding the origins of the steam age (London: Pickering and Chatto, 2009).

48 Courrier de l'Europe (September 1784), 24.

49 Jan Golinski, "Conversations on Chemistry: Talk about phlogiston in the Coffee House Society, 1780-1787," Trevor Harvey Levere and Gerard L'Estrange Turner, eds., Discussing Chemistry and Steam: The minutes of a coffee house philosophical society, 1780-1787 (Oxford: Oxford University Press, 2002), 191-205; Peter Jones, Industrial Enlightenment: Science, technology and culture in Birmingham and the West Midlands 1760-1820 (Manchester: Manchester University Press, 2008).

5o John Perkins, "Creating Chemistry in Provincial France before the Revolution: The examples of Nancy and Metz," Ambix 51 (2004): 4375. 
injection of hot air and complemented theoretical essays on "the noxious and mephitic air of cesspools" that he presented at the local academy. ${ }^{51}$

The fact that debates surrounding the identity of aerial fluids rested on recognizing their characteristics demonstrates that these men were no less informed or capable of tackling issues relating to 'airs' than their better-known academic contemporaries. They evolved within the same epistemic world, offering solutions to mastering steam and fire, producing hydrogen and purifying the atmosphere of carbon dioxide. Their activities helped to shape both the intellectual boundaries of 'air' and a social world through the design of artifacts. The outlines of the social milieux engaged with 'airs' shed light on new arenas of practices and exchanges where different communities interacted, creating opportunities to speculate about the concrete expectations of 'airs' aroused in the public sphere. This was particularly the case with the prevention of hazards that aimed at disciplining urban spaces and spreading social reform. In ancien regime Paris, prefiguring the creation of the Committee for Salubrity in 1791, public authority and the politics of regulation fostered much expertise dedicated to salubrity. Skilled chemists such as d'Arcet or Cadet de Vaux supervised a large field of research that connected hygiene and philanthropy. ${ }^{52}$ The nature of 'airs' was not only discussed in restricted areas such as Royal Society of Medicine, but also staged through experiments in the center of the city, that linked a variety of public buildings with risk-filled places such as mines, cesspools and rivers, targeting both injured workers and drowned people. ${ }^{53}$ They generated new expectations in the public sphere by staging "miracles of chemistry" that underlined the "real solutions" offered to the city's "suffering humanity" by a discipline that had been freed from its old formulas. ${ }^{54}$ Mastery of air was one among many 'miracles' provided by chemistry. Prompting a large number of essays, prints and explanations, discussions

"Extrait d'une lettre écrite par Boin correspondant de l'académie de Rouen," in the section "Observations sur le froid de l'hiver de 1776," Oeuvres de Lavoisier, vol. 3, 394; Annnonces (see note 37); "Sur le méphitisme des fosses d'aisances (1781)," in "Liste des mémoires lus à l'Académie dans ses séances particulières et publiques, depuis 1781 jusqu'en 1793," Précis analytique des travaux de l'Académie royale des sciences, belles-lettres et arts de Rouen, depuis sa fondation en 1744 jusqu'à l'époque de sa restauration 5 (Rouen, 1821): 16.

$5^{2} \quad$ Le Roux, Le laboratoire des pollutions industrielles (see note 28).

53 Thébaud-Sorger, "Innovation and Risk Management," (see note 28); Philippe-Nicolas Pia, Avis patriotique concernant les personne suffoquées par la vapeur de charbon qui apparaissent mortes et qui ne l'étant pas, peuvent recevoir des secours pour être rappelées à la vie (Paris: Veuve Thiboust, imprimeur du roi, 1776).

54 Louis-Sébastien Mercier, Tableau de Paris (Hambourg: Virchaux \& co., 1781), volume 1, chapter 53 «Air vicié,» 62 . 
occurred in various social spaces that interacted with the development of a chemistry embedded in wider debates. A directory of practical solutions was explored by a great variety of actors, in and beyond academic circles. The interaction between air and the city, seen as a living organism, facilitated a reconciliation between and convergence of investigations into nature and social reform.

\section{Conclusion}

This essay has shown how devices used to contain 'airs' reorganized the sociomaterial world around them and reshaped the environment at the end of the eighteenth century. Inventive practitioners aspired not only to capture invisible fluids but also to modify their actions, and even to produce them artificially. Each device they created comprised a material arrangement that might perform the impossible: resuscitation, mastering fire and heat, using the power of steam for daily comfort and transforming the irrespirable atmosphere into breathable air.

Embodied in various adaptable commodities, apparatus and objects designed to perform useful actions, a new material culture brought about a concretisation of gases, heat and steam. This entailed a mixture of sounds, smells, movements, changes of temperature and changes in the size and shape of containers. On a broader scale, it brought together chemical practice and an evolving culture of consumption in ways that gradually changed society and the urban landscape. These devices were not necessarily designed to serve just one purpose but were, on the contrary, intended to be transferred and applied to a great variety of contexts: urban, rural, industrial, domestic and public. From lighting streets and theaters to preventing fires, resuscitating drowned people and overcoming gravity, these devices exhibited a wide range of possibilities that fostered the creation of a heterogeneous network of practitioners who understood and promoted their intensive development for new purposes. ${ }^{55}$

Many "improvers" were engaged in a synthetic approach based on comparisons, analogies, reconciliations, convergences and proportions, that engaged with some of the most recently generated knowledge on materials and substances. They thereby contributed to the further understanding of the 'airs' they sought to master. These persons were not just academic figures or typical projectors, but hybrid entrepreneurs, craftsmen, lecturers, manufacturers, 
administrators, physicians, apothecaries, architects and clergymen. Their identities drew on a whole gallery of Enlightenment occupations. They contributed through their material devices to the creation of a new oeconomy of nature, which intersected with social expectations, the market place and entrepreneurial strategies in addition to the governance of matter.

Far from seeing this complex process in terms of the application of theoretical chemical knowledge to practice, this essay's more anthropological approach transcends the supposed opposition between know-how and empirical knowledge, on one side, and theory on the other. It refuses, that is to say, the separation of epistemic investigation from the material arrangements that made it possible. Concentrating on the materiality of devices further affords a historicisation of the distinction between physics and chemistry, and the social distinction between chemists and other practitioners. ${ }^{56}$

Whereas the question of the nature of 'airs' (intersecting with water and fire) was surely a concern of transnational debates, one could argue that the involvement of a much wider audience occurred through advertisements, public displays and experiments; by coming into contact with the everyday experiences of the inhabitants of European cities, this context forged a new culture of the natural elements through demonstrated knowledge of their properties. In conclusion, air stood at the boundary of a whole range of actors, linking diverse activities from industry to public lecturing, and various practices attempting to contain and manage aerial fluids. These labors had transformative sociomaterial effects, taking place in a wide range of sites, creating the grounds for new understandings of air, encouraging new audiences and public interactions, and prompting the creation of a variety of ingenious small-scale inventions.

\section{Acknowledgments}

I would like to thank Liliane Hilaire-Pérez with whom I gave the very first version of this paper in January 2012, "Les techniciens des gaz et de la vapeur au 18e siècle: savoirs, micro-inventions et industrial Enlightenment" at the Research seminar LIED, Paris Diderot Paris 7. My thanks to Delaina Haslam, Simon Werrett and Lissa Roberts for their intensive work revising my text.

$5^{6} \quad$ Jackson, "The 'Wonderful Properties of Glass," p. 68 (see note 6). 